\title{
Are We Losing the Art of Actively Listening to Our Patients? Connecting the Art of Active Listening with Emotionally Competent Behaviors
}

\author{
Michelle Doas \\ Chatham University, Pittsburgh, PA, USA \\ Email: mdoas@chatham.edu \\ Received 15 May 2015; accepted 26 June 2015; published 30 June 2015 \\ Copyright (C) 2015 by author and Scientific Research Publishing Inc. \\ This work is licensed under the Creative Commons Attribution International License (CC BY). \\ http://creativecommons.org/licenses/by/4.0/

(c) (i) Open Access

\begin{abstract}
Active listening is an essential communication technique that requires the listener to focus and provide feedback on what is heard. The ability to listen actively demonstrates sincerity, and assumes that nothing is being shrugged or taken for granted. As a result, active listeners strive to improve professional and personal relationships, decrease misinterpretation of information, strengthen compliance, and foster understanding. Likewise, active listening can foster trust, mutual respect, and patient compliance. This paper will explore vital connections between active listening and displaying emotionally competent behaviors. Additionally, analysis of a case study as a means of strengthening these connections while improving patient outcomes will be assessed.
\end{abstract}

\section{Keywords}

Active Listening, Emotional Competence, Interpersonal Communication

\section{Introduction to Emotional Competence}

Emotional competence is an attribute that is vital to professional nursing practice. Emotional competence refers to the ability to appropriately manage and express one's emotions. Emotionally competent professionals effectively deal with their emotions in interactions, without suppressing others or their emotions. In emotionally competent environments, individuals display a mutual respect for patients and colleagues, an understanding of basic motivations, and a commitment to take responsibility, a desire to correct faulty situations, and the ability to assume full accountability for self-actions and take positive action to correct actions resulting in lack of accoun- 
tability [1].

\section{Characteristics of Emotional Competence}

In work situations and relationships there are five key characteristics of emotional competence [2]:

Self-awareness involves knowing your emotions, reactions associated with emotional interactions, recognizing feelings as they occur, and discriminating between your feelings. Self-awareness in the health care work environment has four stages [3]. First is creating self-awareness of concepts and phenomena. This process involves health care professionals raise questions and possible answer questions using mutually respectful interactions and integrating caring behaviors towards each other and each patient. Second is developing a language that influences thinking. Through both thoughts and dialogue, it is possible to abstract information about what one understands or does not understand. From what is expressed in language and non-verbal communication, it is hoped that one can understand and realize the power associated with behaviors expressed to patients, significant others, families, and coworkers. Third is developing a preferred model of communication. This stage involves talking about one's feelings, assessing the impact of what one says or does in relationship to the reactions in others. Insight makes it possible to support patients in expressing what kind of help is needed or what inner resources they possess. The final stage is reflection. Reflection requires health care professionals to reflect upon the type of care and interpersonal interactions provided. Reflection can be very powerful and result in a better understanding of self, but it requires differentiating between feelings of guilt and strategies to make future interactions more meaningful and positive. For example, it is important to find answers to questions such as, "Why did I snap at the patient and fail to be open-minded?” or "Why didn’t I listen and integrate caring behaviors into my words and actions?” [4].

Mood management involves handling feelings so they are relevant to the current situation. Nurse researchers Healy and McKay [5] found that the use of negativity, avoidance coping, and perception of work overload were significant predictors of mood disturbance which were factors involved in emotional competence.

Self-motivation involves gathering your feelings and directing yourself toward a goal, despite self-doubt, inertia, and impulsiveness.

Self-motivated individuals display positive attitudes, high energy levels, enthusiasm, and overall positive role modeling behaviors. Avery and Bashir [6] suggested that self-motivation could be cultivated by therapeutic interpersonal interactions. For instance, a motivated peer or manager can assist staff with being inspired to have positive daily interactions, provide quality patient care, and develop staff efficiency and overall productivity. Self-motivation is a process that can be nurtured and encouraged by interpersonal warmth, peer support, managerial support, and recognition. Respecting individual capabilities, actively listening, and cultivating new capabilities are instrumental in developing potential and increasing motivation.

Empathy is recognizing feelings in others and tuning into their verbal and nonverbal cues. Emotional empathy allows the health care professional to respond professionally to colleagues or patients in an attempt to meet their needs. An integral part of responding professionally includes accurately synthesizing interpreted words into meaning interventions. According to many experts, emotional empathy is learned by experience and by modeling. Professionals describe this as knowing implicitly what to do with distressed colleagues or patients. The actions resulting from the emotional response or recognition of other's needs are often nonverbal, for example, a touch, a smile, or genuinely listening.

Managing relationships, the final characteristic, is handling interpersonal interactions, conflict resolution, and negotiations in a constructive manner. According to Larson [7], the perceptions of nurses, colleagues, and patients that impact how relationships are managed can vary in a number of respects. For example, the extent to which collaboration and mutual decision making are valued, a shared definition of what constitutes adequate and appropriate interpersonal communication, the quality of interactions, and the understanding of respective areas of responsibility including patients outcomes can all vary. To effectively manage relationships, every human to human interaction should aim at achieving positive outcomes. In order to achieve positive outcomes both active listening and emotionally competent behaviors must be exhibited. Additionally, mutual respect for all must be displayed to avoid interpersonal conflict and ultimately negative outcomes. Lastly, managing relationships involves various skill sets of collaboration and cooperation, promoting a caring and compassionate environment, nurturing opportunities for collaboration and sharing, and displaying mutually respectful behaviors [8].

Collectively, characteristics of self-awareness, mood management, self-motivation, empathy, and managing 
relationships can assist health care providers in cultivating emotionally competent behaviors while instilling active listening techniques.

\section{What Is the Connection between Active Listening and Emotional Competence?}

Active listening (also called empathic or reflective listening) involves a skill set involving listening and responding to another person while displaying mutual understanding and trust. Active listening is an essential skill for health care professionals as it enables the listener to receive and accurately interpret the speaker's message, and then provide an appropriate response. Through active listening, the listener lets the speaker know "I understand your problem and how you feel about it, I am interested in what you are saying and I am not judging you." [9].

Guidelines for Active (empathetic) Listening [10]:

A. Be attentive.

B. Be interested

C. Be alert and not distracted.

D. Create a positive atmosphere through non-verbal behavior.

E. Be a sounding board by allowing the speaker to bounce ideas and feelings off you while assuming A nonjudgmental attitude

F. Don't ask a lot of questions. Questions can give the impression the listener is "grilling" the speaker

G. Act like a mirror by reflecting back what you think the speaker is saying and feeling.

H. Don’t discount the speaker's feeling by using stock phrases like "It's not that bad", or "You'll feel better tomorrow".

I. Don't let the speaker "hook” you. This can happen if you get angry or upset, allow yourself to remain neutral and avoid getting into an argument or passing judgment.

J. Indicate you are listening by:

- Providing brief, noncommittal acknowledging responses, e.g., "Uh-huh”, "I see”.

- Giving nonverbal acknowledgements, e.g., head nodding, facial expression matching the speaker, open and relaxed body expression, eye contact.

- Invitations to say more, e.g., "Tell me about it", "I'd like to hear about that".

K. Follow good listening "ground rules":

- Don't interrupt.

- Don't change the subject or move in a new direction.

- Don't rehear in your own head.

- Don’t interrogate.

- Don't teach.

- Don't give advice.

- Do reflect back to the speaker what you understand and how you think the speaker feels.

\section{Case Study}

Joyce is admitted to the psychiatric unit for uncontrolled anger and suicide ideation. She reports anxiety and a severe headache. Her sister quietly sits beside Joyce making no eye contact. The admitting nurse, Karen orients Joyce to her room and tells Joyce she has to check the physician orders but will get something for her headache. The unit is busy and Karen is not able to return for 45 minutes. She finds Joyce crying, angry, and demanding to go home. Karen gives Joyce pain medication then invites Joyce and her sister into a small conference room. She sits facing them while maintaining eye contact and says, “I am so sorry I didn't come sooner. How can I help you now?” Initially Joyce remains angry but Karen gently persists in telling Joyce she wants to help her. After a few minutes Joyce and her sister proceed to tell Karen how long they sat in the ER and waited "forever" to be transferred yet still have no idea what is happening. Karen relaxes in her chair and softly begins to explain unit protocol, group meetings, scheduling, and answers Joyce and her sister's questions in a relaxed and respectful manner.

\section{Case study Analysis}

Analysis of this patient case study prompts one to assess the nurse's ability to actively listen to the patient and 
her sister. Concepts associated with active listening were implemented. For example, being attentive, maintaining eye contact, assuming no judgment, and acknowledging previous experiences prior to being admitted.

So, what is the link between active listening, emotional competence and patient outcomes? Based upon the above case study, one has to reflect upon patient outcomes and actions of the active listening/emotionally competent nurse versus an inability to actively listen. As illustrated in the case study, the patient complied with seeking ER evaluation based upon physical and emotional symptomology. Likewise, the nurse integrated active listening techniques including mutual understanding, gaining trust, and accurate interpretation. Additional techniques adding to the effectiveness of active listening in the case study included integrating emotionally competent characteristics, including self-awareness, self-motivation, empathy, and managing relationships.

How can awareness of active listening and emotionally competent behaviors be communicated to nurses and health care providers? According to Travaline [11] reminders include:

- Assess what the patient already knows

- Assess what the patient wants to know

- Be empathetic

- Slow Down

- Keep it Simple

- Tell the Truth

- Be Hopeful

- Watch the Patient's Body and Face

- Be prepared for a Reaction

Based upon the above reminders, simple choices in words, information depth, speech patterns, body position, and facial expression can greatly affect the quality of one-to-one communication between patient and health care provider. It should be noted that the above reminders are conscious choices that can be learned and customized by the health care provider to fit specific patient interactions and clinical situations. Engagement in active listening techniques and integration of emotionally competent behaviors can assist in avoiding communication pitfalls and promote quality based patient outcomes.

\section{Implications for Practice}

For nurses and health care professionals failure to actively listen has been blamed as a cause for improper diagnosis or inadequate treatment. The therapeutic effects of active listening have been stressed for decades by various authors. Additionally, the Joint Commission continually advocates for health care worker's to consistently implement active listening techniques and overall effective communication skills among all patient populations. As a result, active listening skills need to be revisited and cultivated in order to provide more accurate patient assessments, quality based outcomes, and a positive patient experience.

Based upon previously conducted studies; nurses, health care professionals and educators should attempt to integrate the five key characteristics of emotional competence and active listening techniques into day to day interactions, staff development education and annual competency requirements. Integration of these techniques can create awareness and increase patient compliance and positive patient outcomes.

\section{Conclusion}

Ongoing strategies for recognizing the value of active listening and emotional competence can be cultivated by assessing the health care provider's skill levels and behaviors. Nursing management gurus Dreyfus [6] proposed a five level skill acquisition model for emotional competence assessment. This five level skill acquisition model can be applied to assessing one's active listening skill set. It should be noted the novice usually has a basic understanding of emotionally competent behaviors and active listening techniques. These individuals are intuitively aware of individual interaction styles, behaviors, and possible outcomes but have minimal experience with interpersonal conflicts.

The advanced beginner may have a limited amount of open-mindedness toward others and leans toward being biased and/or judgmental. However, this group may have a good degree of self-awareness related to feelings and interpersonal interactions and are gaining confidence in shared decision making. These individuals are able to reflect upon the meaning of interactions, value of actively listening, ability to think about possible consequences related to specific behaviors/interactions and outcomes. It should be noted these individuals may become dis- 
couraged rather easily in difficult emotional situations.

At the competent level the individual is becoming more open-minded toward others and beginning to see value of collaborating and actively listening. Additionally, compassion and caring behaviors are more apparent. These individuals most often appreciate the value of listening, shared decision making, and mutual goal setting, and can reflect upon the value of feelings while appreciating individual differences. This group is usually inclined to actually cultivate effective communication skills, including nonverbal behaviors, and is developing impulse control.

At the proficient level, the individual highly values integrity, mutual respect, and goal setting. These individuals attempt to effectively manage negative emotions and display professional impulse control; attitudes are more positive than negative. This group is more able to identify interpersonal stressors/conflicts and implement nonjudgmental interventions. The proficient individual most often sees the value of individual differences, therapeutic communication, including active listening, and displays caring and compassion towards others.

At the expert level, the individual consistently demonstrates open-mindedness, active listening skills and sees self-assessment behaviors as a way to grow personally and professionally. These individual's value being proactive versus reactive, seek out collaborative opportunities, and value individual differences. Experts understand that negativity will surface but do not feed into others' negativity; instead, positive impulse control is consistently displayed. Based upon the outcomes of the case study, it is evident that the nurse, Karen, demonstrates interpersonal skills at both the proficient and expert levels.

Nurses and health care professionals must be able to define and describe active listening techniques and an ideal emotionally competent work environment along with assessing personal skill level acquisition. Assessment of emotionally competent behaviors and active listening techniques can assist individuals to engage in, co-create, and support relationships of mutual respect, presence, and professional growth. Realizing the true power of the spoken word is a vital component of the overall assessment process. Additionally, an emotionally competent/ active listening environment can be transferred to all patient interactions, resulting in positive outcomes on many levels. Likewise, these skills are vital since all health care professionals are pivotal in creating awareness of the importance of engaging in active listening and emotionally competent behaviors, analyzing clinical behaviors and patient outcomes, integrating evidence based interventions and creating a mutual plan for cultivating emotional competence in all patient interactions.

\section{References}

[1] Porter-O’Grady, T. and Malloch, K. (2007) Quantum Leadership: A Resource for Health Care Innovation. Jones \& Bartlett, Sudbury

[2] Sharp, P. (2001) Nurturing Emotional Literacy: A Practical Guide for Teachers, Parents and Those Working in the Caring Professions. David Fulton, London.

[3] Severson, E. (2001) Confirmation, Meaning and Self-Awareness as Core Concepts of the Nursing Supervision Model. Nursing Ethics, 8, 36-44. http://dx.doi.org/10.1177/096973300100800105

[4] Doas, M. (2013) What Are the Potential Outcomes of Integrating Emotionally Competent Behaviors into the Care of Psychiatric Patients? Journal of Psychiatric and Mental Health Nursing, 20, 405-410. http://dx.doi.org/10.1111/j.1365-2850.2012.01931.x

[5] Healy, C. and McKay, M.F. (2000) Nursing Stress: The Effects of Coping Strategies and Job Satisfaction in a Sample of Australian Nurses. Journal of Advanced Nursing, 31, 681-688. http://dx.doi.org/10.1046/j.1365-2648.2000.01323.x

[6] Avery, B. and Bashir, S. (2003) The Road to Advocacy-Searching for the Rainbow. American Journal of Public Health, 93, 1207-1210. http://dx.doi.org/10.2105/AJPH.93.8.1207

[7] Larson, E. (1999) The Impact of Physician-Nurse Interaction on Patient Care. Holistic Nursing Practice, 13, 38-46. http://dx.doi.org/10.1097/00004650-199901000-00007

[8] Doas, M. (2011) Is Emotional Competence a Viable Component in Today's Work Environment? Journal for Nurses in Staff Development, 27, 206-209. http://dx.doi.org/10.1097/NND.0b013e3181dfc9d2

[9] Salem, R. (2011) Empathetic Listening \& Dispute Resolution. Community Dispute Resolution, ADR Times: Alternative Dispute Resolution Insights \& Resources.

[10] Burley-Allen, M. (1982) Listening to the Forgotten Skill. John Wiley \& Sons, Hoboken.

[11] Travaline, J.M. Ruchinskas, R. and D’Alonzo Jr., G.E. (2005) Patient-Physician Communication: Why and How. The Journal of the American Osteopathic Association, 105, 13-18. 